Revista de Derecho YACHAQ N. ${ }^{\circ} 8$ - Diciembre de 2017

Centro de Investigación de los Estudiantes de Derecho (CIED)

Universidad Nacional de San Antonio Abad del Cusco

ISSN: 2707-1197 (en linea)

ISSN: 1817-597X (impresa)

Fecha de recepción:

Fecha de aceptación:

[pp. 107-120]

\title{
Industria De Los Hidrocarburos En Venezuela:
}

\author{
TRINIDAD DE ROLES DEL ESTADO-ANFITRIÓN E IMPORTANCIA DE LOS PRINCIPALES SISTEMAS \\ JURÍDICOS DEL MUNDO*
}

\section{HYdROCARBon INDUSTRY In VENEZUELA: TRINITY OF ROLES OF THE HOST-STATE AND IMPORTANCE OF THE PRINCIPALS LEGAL SYSTEMS OF THE WORLD *}

\author{
César Rafael Mata García \#
}

\begin{abstract}
Resumen: El presente artículo busca despertar curiosidad académica sobre uno de los principales problemas que enfrentan los distintos actores que conforman la industria de los hidrocarburos : su coexistencia con los distintos roles y funciones del Estado-Anfitrión en el negocio petrolero y gasífero, y sobre la relevancia de la interpretación y aplicación de normas jurídicas a la anterior coexistencia en controversias y/o discrepancias nacionales e internacionales, en particular, cuando son estudiadas y analizadas bajo los principios propios de los principales sistemas jurídicos del mundo. Lo anterior ha llevado, en la práctica, a análisis e interpretaciones de instituciones jurídicas conformes al sistema de Derecho Civil, pero bajo la óptica y análisis de conceptos e instituciones propios del Derecho Común (y/o viceversa), como sería, por ejemplo, el caso de la coexistencia del principio de supremacía del interés colectivo y el principio de autonomía de la voluntad de las partes sobre el desarrollo de los negocios de la industria de los hidrocarburos.
\end{abstract}

\begin{abstract}
This article seeks to awakening the academic curiosity about one of the main problems faced by different actors that make up the hydrocarbon industry: Its coexistence whit the different roles and functions of the HostState in the oil and gas business about the relevance of the interpretation and application of legal norms to the previus coexistence in national and international controversies and/or discrepancies, in particular when these are studied and analyzed under the own values of the main legal systems of the world. The foregoing has led, in practice, to analysis and interpretations of legal institutions in accordance with the Civil Law system, but from the perspective

\footnotetext{
* El material utilizado para la elaboración y redacción del presente artículo académico es parte de los Capítulos I y VI del libro intitulado Manual de Derecho de los Hidrocarburos en Venezuela, Venezuela, Editorial Arte, 2016, escrito por César R. Mata García. Disponible en Amazon.com.

\# Doctor $(\mathrm{PhD})$ en Derecho y Magíster en Derecho y Política Petrolera egresado del Centro para el Derecho y Política Energética, Petrolera y Minera de la Universidad de Dundee (Escocia-Reino Unido). Es Abogado egresado de la Universidad Católica Andrés Bello (Venezuela). Asesor Legal de la Cámara Petrolera de Venezuela, Profesor Agregado de la Universidad Metropolitana (Venezuela), Profesor Honorario en el Centro para el Derecho y Política Energética, Petrolera y Minera de la Universidad de Dundee (Escocia-Reino Unido); escritor en temas legalesenergéticos a nivel nacional e internacional.Cmatagarcia@gmail.com
} 
and analysis of concepts and institutions of the Common Law, as would be, for example, the case of the coexistence of the principle of supremacy of the collective interest and the principle of autonomy of the will of the parties regarding the development of the hydrocarbon industry business.

Palabras claves: Venezuela, Industria de los hidrocarburos, Hidrocarburos líquidos, Hidrocarburos gaseosos, Estado-Anfitrión, Estado-Propietario, Estado-Regulador/Administrador, Estado-Empresario/Socio, Sistemas jurídicos, Derecho Civil, Derecho Común, Reserva legal, Propiedad.

Keywords: Venezuela, Hydrocarbon industry, Liquid hydrocarbons, Gaseous hydrocarbons, Host-State, StateOwner, State-Regulator/Administrator, State-Entrepreneur/Partner, Legal systems, Civil law, Common Law, Legal reserve, Property. 


\section{1.- Introducción}

$\mathbf{U}$ no de los principales problemas que enfrentan los distintos actores que conforman la industria de los hidrocarburos es su coexistencia con los distintos roles y funciones del Estado-Anfitrión en el negocio petrolero y gasífero, así como la relevancia de la interpretación y aplicación de normas jurídicas derivadas de la anterior coexistencia, en particular, cuando son estudiadas y analizadas -en controversias y/o discrepancias- bajo los principios propios de los principales sistemas jurídicos del mundo. Este ejercicio puede provocar análisis e interpretaciones de instituciones jurídicas propias del sistema de Derecho Civil, pero bajo la óptica y análisis de conceptos e instituciones propias del Derecho Común como sería el caso de la coexistencia del principio de supremacía del interés colectivo y el principio de autonomía de la voluntad de las partes en los negocios de la industria de los hidrocarburos ${ }^{1}$.

Las principales preocupaciones de los inversionistas en materia petrolera y gasífera es la relación de propiedad, regulatoria, económica y contractual que deben mantener con los distintos órganos o entes que materializan las funciones del Estado-Anfitrión. En efecto, la industria de los hidrocarburos debe coexistir, en la mayoría de los países, con múltiples roles y funciones que tiene y posee el Estado-Anfitrión para el constante, óptimo y garantizado desarrollo de sus actividades comerciales.

La mencionada industria de los hidrocarburos está conformada no solo por los países productores y consumidores; sino también por otros actores (públicos y privados) como lo son la República, el Gobierno (i.e., Poder Ejecutivo), las empresas operadoras nacionales e internacionales, las empresas de servicios, los refinadores, los industrializadores, los comercializadores y los consumidores finales. Todos ellos ejercen las actividades que conforman la denominada Cadena de Valor de los Hidrocarburos ${ }^{2}$, que va desde la búsqueda de hidrocarburos en el subsuelo hasta su procesamiento y venta al detal. El ejercicio de las actividades que conforman la mencionada Cadena de Valor requiere de la autorización o la participación del Estado-Anfitrión, mediante cualquier de sus tres principales roles, como se verá en el sub-título II del presente artículo.

La importancia de la anterior relación jurídica, entre los actores de la industria de los hidrocarburos y el EstadoAnfitrión, toma mayor relevancia, como se desarrollará en el sub-título III del presente artículo, cuando debe

\footnotetext{
${ }^{1}$ Véase, para mayor detalle sobre este punto: Mata García, C. R., (2016) International Investment and Regulatory Disputes - Applying Principles of Administrative Law to Investor-State Treaty Arbitrations, Germany, Scholar's Press.

${ }^{2}$ La Cadena de Valor de los Hidrocarburos está conformada principalmente por las actividades de exploración, perforación, extracción, recolección, almacenamiento, utilización, refinación, procesamiento, comercio exterior, industrialización, comercio interior, transporte, almacenamiento, suministro, distribución y expendio.
} 
tomarse en cuenta la interpretación y el sistema jurídico utilizados ante una discrepancia o diferencia que pueda surgir entre la acción o el documento que da origen la relación de propiedad, regulatoria, económica o contractual entre cualquier o varios de los actores de la industria de los hidrocarburos y el Estado-Anfitrión.

\section{2.- Industria de los hidrocarburos en Venezuela versus trinidad de roles del Estado-Anfitrión}

En Venezuela, con la aprobación y promulgación de la Constitución de la República de 1999, se elevaron a rango constitucional distintos conceptos que se encontraban dispersos en varias normas de rango legal. Entre ellos, la de la propiedad de la República sobre los yacimientos de hidrocarburos, la cual se consideraba reconocida desde la promulgación en Quito del Decreto de El Libertador, en 1829; la de la reserva legal de la actividad petrolera que derivaba de la Ley de Nacionalización de 1975; y la de la reserva de las acciones de la empresa Petróleos de Venezuela, S.A. (PDVSA) al Estado venezolano, creada mediante Decreto en 1975.

Estos conceptos dan lugar a lo que se puede conocer como la trinidad de roles del Estado venezolano en el negocio de los hidrocarburos, conformada por el Estado-Propietario de los yacimientos de hidrocarburos (Const., 1999, art. 12), el Estado-Regulador/Administrador de la reserva legal de actividades relativas al uso y aprovechamiento de los hidrocarburos ${ }^{3}$ (Const., 1999, art. 302), y por último, el Estado-Empresario/Socio, que participa directamente o mediante sociedad con terceros en el mencionado uso y aprovechamiento de los hidrocarburos (Const., 1999, art. 303). En el siguiente gráfico, se puede visualizar la trinidad de roles que posee el Estado sobre la libre disposición, uso y aprovechamiento de los hidrocarburos en Venezuela.

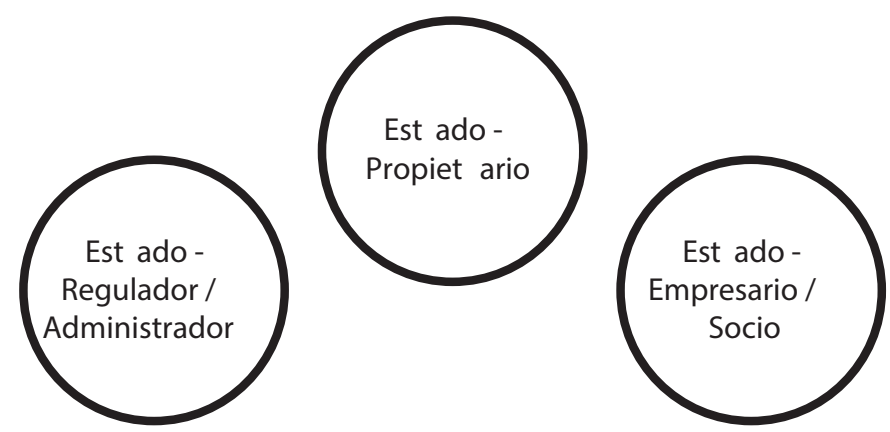

Corresponde en consecuencia al presente sub-título, estudiar las principales normas constitucionales que regulan a los hidrocarburos y sus actividades en Venezuela, en el marco de la trinidad de roles que tiene el Estado en la industria de los hidrocarburos. Al efecto, se ha dividido este sub-título en tres principales áreas conforme al gráfico mencionado: propiedad de los yacimientos; reserva legal de la actividad petrolera al Estado; y reserva de las acciones de la empresa estatal Petróleos de Venezuela, S.A. (PDVSA - Casa Matriz).

\section{1.- Propiedad de los yacimientos (Estado-Propietario)}

El Artículo 12 de la Constitución de Venezuela establece, dentro de los fundamentos relativos al Espacio Geográfico y la División Política del país, y en especial, en lo relativo al Territorio y demás Espacios Geográficos, que “ $\underline{\text { los }}$

\footnotetext{
3 Como se verá más adelante, la Constitución de Venezuela del año 1999, en su Artículo 302, habla de la reserva de la industria petrolera. Al respecto, es oportuno resaltar acá si el Constituyente cuando se refiere a la industria petrolera también se refiere a la gasífera.
} 
vacimientos mineros y de hidrocarburos, cualquiera que sea su naturaleza, existentes en el territorio nacional bajo el lecho del mar territorial, en la zona económica exclusiva y en la plataforma continental, pertenecen a la República, son bienes del dominio público y, por tanto, inalienables e imprescriptibles..." (subrayado del autor).

De esta manera, dicha norma consagra la propiedad de la República sobre sus yacimientos mineros y de hidrocarburos en todo el territorio nacional, pero también resalta la inalienabilidad e imprescriptibilidad de dichos yacimientos. Estas dos últimas figuras jurídicas son propias del Derecho Civil, que se traducen, a su vez, en la imposibilidad de constituir garantías sobre dichos yacimientos, así como adquirirlos por cualquier medio legal relativo a la posesión legal o usucapión $^{4}$.

Para comprender el alcance territorial de lo previsto en el Artículo 12 de la Carta Magna ${ }^{5}$, debe tomarse en cuenta el Artículo 10 del mismo texto constitucional que delimita lo que se entiende por Territorio Nacional, es decir, "el territorio nacional y demás espacios geográficos de la República son los que correspondían a la Capitanía General de Venezuela antes de la transformación política iniciada el 19 de abril de 1810, con las modificaciones resultantes de los tratados y laudos arbitrales no viciados de nulidad".

De igual modo, el ejercicio de los anteriores principios constitucionales se realiza conforme al Artículo 11 de la Constitución, que establece que "la soberanía plena de la República se ejerce en los espacios continental e insular, lacustre y fluvial, mar territorial, áreas marinas interiores, históricas y vitales y las comprendidas dentro de las líneas de base rectas que ha adoptado o adopte la República; el suelo y subsuelo de estos; el espacio aéreo continental, insular y marítimo y los recursos que en ellos se encuentran, incluidos los genéticos, los de las especies migratorias, sus productos derivados y los componentes intangibles que por causas naturales allí se hallen".

Las anteriores bases constitucionales son las que dan forma a lo que se conoce como el Estado-Propietario, a diferencia de sus otros dos roles como Estado-Administrador/Regulador y Estado-Empresario/Socio, que se considerarán más adelante.

Es importante para el lector tener clara la delimitación de cada rol, ya que en la práctica se encuentran casos en los que un mismo funcionario ejerce varios roles y funciones, lo que hace necesario saber con antelación bajo qué rol y cuál responsabilidad está actuando dicho funcionario. Solo mediante el anterior ejercicio, se puede saber con cuánta firmeza se está avanzando en una determinada negociación o relación jurídica con el Estado-Empresario/Socio. En otros términos, se alude a la diferenciación y delimitación de lo que se conoce -en Derecho Público- como actos de dominio (iure imperii) y actos de administración o gestión (iure gestionis).

En la línea del concepto del Estado-Propietario, es importante citar la norma constitucional que reconoce el Derecho de Propiedad en Venezuela.

\footnotetext{
${ }^{4}$ Se recomienda leer el Capítulo II del libro de Rondón de Sansó, H., (2008) El régimen jurídico de los hidrocarburos. El impacto del petróleo en Venezuela, Caracas, Hildegard Rondón de Sansó, donde hace un estudio detallado de los principios establecidos en el Código Civil venezolano, sobre la clasificación de los bienes con relación a las personas a quienes pertenecen.

5 (DIPUTADOS DE LA ASAMBLEA CONSTITUYENTE, 1999)

6 Se recomienda igualmente leer el Capítulo II del libro de Rondón de Sansó, H., ibidem, donde hace un estudio detallado de las figuras relativas al uti possidetis iure y al uti possidetis de facto.
} 
Al efecto, el Artículo 115 de la Constitución establece que "se garantiza el derecho a la propiedad. Toda persona tiene derecho al uso, goce, disfrute y disposición de sus bienes...”. Sin embargo, el mencionado Artículo continúa diciendo que "la propiedad estará sometida a las contribuciones, restricciones y obligaciones que establezca la ley con fines de utilidad pública o de interés general ..." (subrayado del autor), lo que sirve como referencia para el lector a los fines de comprender que el derecho a la propiedad en Venezuela no es un derecho absoluto, y que el mismo está sujeto a las restricciones establecidas en el ordenamiento jurídico venezolano?

Dentro de la anterior idea, cabe destacar para el lector conocer que el Artículo 115 en referencia menciona la facultad que tiene el Estado de declarar la expropiación sobre cualquier clase de bienes, pero solo cuando la solicitud de la misma esté fundada en causa de utilidad pública o interés social, para lo cual deberá existir i) sentencia firme y ii) el pago oportuno de una justa indemnización.

Es oportuno resaltar que en Venezuela, la totalidad de las actividades correspondientes a la Cadena de Valor de los Hidrocarburos son declaradas, en las respectivas leyes de petróleo y de gas, de utilidad pública.

El Estado venezolano ha sido parte activa en el proceso de reconocimiento del principio internacional de Soberanía Permanente sobre los Recursos Naturales en áreas específicas como las de los hidrocarburos. Ejemplo reciente de ello, se encuentra en la reformulación de este principio internacional bautizado localmente como el de la Plena Soberanía Petrolera, el cual ha servido de marco para la toma de decisiones y formulación de políticas públicas en la industria de los hidrocarburos en los últimos tiempos, y en especial, la adopción de un conjunto de normas legales y sub-legales que regulan -de manera restringida- la actividad de los hidrocarburos en Venezuela. Para algunos, dichas normas se han traducido y entendido como la ratificación de la propiedad del Estado venezolano sobre sus recursos naturales.

\section{2.- Reserva legal de la actividad petrolera (Estado - Regulador / Administrador)}

El Artículo 302 de la Constitución, ubicado dentro del Título correspondiente al diseño del sistema socioeconómico del país, específicamente en el Capítulo relativo al Régimen Socioeconómico y la Función del Estado en la Economía, designa al Estado, bajo las condiciones establecidas en la Ley orgánica respectiva, como Estado-Administrador/ Regulador de las actividades relativas a la industria petrolera.

Al efecto, dicha norma constitucional establece que "El Estado se reserva, mediante la ley orgánica respectiva, y por razones de conveniencia nacional, la actividad petrolera y otras industrias, explotaciones, servicios y bienes de interés público y de carácter estratégico...” (subrayado del autor).

De la anterior transcripción se desprenden tres elementos que requieren especial atención: i) la reserva mediante Ley orgánica, ii) la actividad petrolera, y iii) otras industrias relacionadas.

\footnotetext{
${ }^{7}$ Para mayor detalle sobre el régimen legal aplicable a la limitación del derecho a la propiedad en Venezuela, se recomienda revisar bibliografía referente a Badell Madrid, R., Limitaciones al derecho de la propiedad. Disponible en <http://www.badellgrau.com/?pag=45\&ct=1085>. (Consultado: 21 de diciembre de 2016). Ver también Gordillo, A., (2002) Tratado de Derecho Administrativo, Caracas, Fundación de Estudios de Derecho Administrativo, tt. I, II, III y IV.
} 
Con relación al primer elemento sobre la reserva legal mediante Ley orgánica, es importante recordar que en 1975, a través de la Ley Orgánica que Reserva al Estado la Industria y el Comercio de los Hidrocarburos (Ley de Nacionalización de 1975) ${ }^{8}$, el Estado se reservó todas las actividades relativas al uso y aprovechamiento de los hidrocarburos (líquidos), quedando la reserva legal de los hidrocarburos gaseosos sujeta a las normas contenidas en la Ley que Reserva al Estado la Industria del Gas Natural de 1973.

Sin embargo, para el año 1999 el Ejecutivo nacional, mediante una ley habilitante, promulgó una nueva Ley para la industria del gas que derogó la Ley de 1973, lo que eliminó la reserva legal del Estado sobre dicha industria del gas, abriendo de este modo la industria de los hidrocarburos gaseosos no asociados en un $100 \%$ a la participación privada.

Por su parte, la industria de los hidrocarburos líquidos pasó de estar bajo una reserva legal absoluta, declarada mediante la Ley de Nacionalización de 1975 sobre todas las actividades que conformaban la industria de los hidrocarburos líquidos, a estar bajo una reserva legal parcial y delegada, la cual es desarrollada en la Ley Orgánica de los Hidrocarburos (líquidos) de 2001 (reformada parcialmente en 2006). En efecto, el Artículo 9 de la mencionada Ley Orgánica de Hidrocarburos solo reserva al Estado las actividades de extracción de los hidrocarburos naturales, su recolección, transporte y almacenamiento inicial, conocidas como las actividades primarias. De este modo, se dejan -en principio- las otras actividades relativas a los hidrocarburos como refinación, industrialización y comercialización abiertas en un $100 \%$ a la inversión privada.

Con relación al segundo elemento que requiere atención, resulta importante hacer referencia a la redacción del Constituyente cuando habla de la reserva de la industria petrolera, mediante Ley orgánica. Como se puede apreciar, el Constituyente hace mención expresa a la industria petrolera, lo que lleva a cuestionar si el Constituyente también deseaba incluir en dicho concepto a la industria del gas natural. De hecho, lo que sí pareciera estar claro es la intención del legislador de mantener separadas ambas industrias. Como reflexión a esta última intención se puede pensar que basados en las normas adoptadas durante los años 1999 (Ley Orgánica de Hidrocarburos Gaseosos) y 2001 (Ley Orgánica de Hidrocarburos), las ideas eran: i) que el Estado mantuviera separadas ambas industrias mediante regímenes legales distintos, y ii) que la redacción del Artículo 302 no incluyese a la industria de gas natural. Esto último es la reconfirmación de la exclusión de la mencionada industria/actividad del gas natural de la reserva legal absoluta, promovida por el Estado mediante la Ley de Nacionalización de 1975.

Respecto al tercer elemento sobre la reserva legal de otras industrias relacionadas, se encuentra que el Constituyente hace referencia a la reserva legal por razones de interés público y de carácter estratégico de otras industrias, explotaciones, servicios y bienes.

La importancia de la posibilidad de reservarse legalmente otras industrias, explotaciones, servicios y bienes, se encuentra en los parches de la parcial reserva legal que -en la actualidad-se han adoptado para recuperar la idea original de la reserva absoluta (nacionalización) de la industria petrolera nacional; es decir, se han adoptado acciones que inconsistentemente han regulado y desregulado el sector de los hidrocarburos; como es el caso de la fluctuación

${ }^{80}$ Ley que reserva al Estado la Industria y el Comercio de los Hidrocarburos, conocida como Ley de Nacionalización, promulgada el 29 de agosto de 1975. 
del alcance de la reserva legal que ha tenido lugar mediante la Ley Orgánica que Reserva al Estado la Industria y el Comercio de los Hidrocarburos de 1975 (Ley de Nacionalización), Ley que Reserva al Estado la Industria del Gas Natural de 1973, Ley Orgánica de Hidrocarburos Gaseosos de 1999 y Ley Orgánica de Hidrocarburos (líquidos) de 2001.

Adicionalmente, dentro de la posibilidad de reservar legalmente otras industrias, explotaciones, servicios y bienes, se encuentra también la promulgación de normas ocasionales que buscan recuperar la anterior idea original de reserva legal absoluta sobre la industria de los hidrocarburos en Venezuela. Ejemplo de ello se encuentra en la reserva al Estado de algunas actividades de la Cadena de Valor de los Hidrocarburos (líquidos) tales como: i) las actividades conexas a las actividades primarias ${ }^{9}$, y ii) algunas actividades relacionadas con el comercio y suministro nacional de productos derivados de los hidrocarburos líquidos ${ }^{10}$.

En la práctica, este último caso manifiesta la adopción de normas que son completamente legales, pero descontextualizadas conforme a la experiencia y lecciones obtenidas durante el desarrollo de la historia petrolera de Venezuela, por no seguir un plan de Estado consistente para el desarrollo de la industria de los hidrocarburos en Venezuela. Ello, porque debe tenerse claro que una cosa es garantizar la propiedad sobre los yacimientos de hidrocarburos (Const., 1999, art.12), y otra es el alcance de la reserva legal sobre actividades industriales para el uso y aprovechamiento de esos yacimientos de hidrocarburos (Const., 1999, art. 302, $1^{\text { }}$ Párr.).

Al igual que sucede con el alcance de la reserva legal sobre el uso y aprovechamiento de los hidrocarburos en Venezuela, un texto de la Constitución que se presta a confusión de manera constante en la práctica legal es el segundo párrafo del Artículo 113, el cual reza: “... Cuando se trate de explotación de recursos naturales propiedad de la Nación o de la prestación de servicios de naturaleza pública con exclusividad o sin ella, el Estado podrá otorgar concesiones por tiempo determinado, asegurando siempre la existencia de contraprestaciones o contrapartidas adecuadas al interés público" (subrayado de autor).

En este Artículo resaltan dos elementos que requieren atención y aclaratoria: i) concesiones por parte del Estado, por un tiempo determinado, ii) para la explotación de recursos naturales propiedad de la República.

El Constituyente habla de la posibilidad de obtener concesiones para la explotación de recursos naturales, dentro de los cuales podría, a primera vista, incluirse los hidrocarburos en general, es decir líquidos, gaseosos, semisólidos y sólidos. Sin embargo, es importante destacar que ante la reserva legal consagrada en el Artículo 302 antes considerada y delegada en una Ley orgánica especial, las actividades relativas a la explotación de los hidrocarburos (líquidos) en Venezuela solo pueden realizarse conforme a los términos y condiciones consagrados en dicha ley especial, es decir, en la Ley Orgánica de Hidrocarburos de 2001 (reformada parcialmente en 2006).

Ahora bien, una duda válidamente surgiría sobre la posibilidad de los particulares de optar por una concesión para el ejercicio de las actividades relativas al uso y aprovechamiento de los hidrocarburos gaseosos (gas natural) en Venezuela, los cuales, como se vio anteriormente, no están incluidos expresa y claramente en la reserva contemplada

\footnotetext{
${ }^{9}$ Ver Ley Orgánica que Reserva al Estado los Bienes y Servicios Conexos a las actividades primarias de los Hidrocarburos. Gaceta Oficial de la República Bolivariana de Venezuela No 39.173 del 7 de mayo de 2009

10 Ver Ley Orgánica de Reordenamiento del Mercado Interno de los Combustibles Líquidos. Gaceta Oficial de la República Bolivariana de Venezuela No 39.019 del 18 de septiembre de 2008.
} 
en el primer párrafo del Artículo 302. Sin embargo, es oportuno señalar al respecto que la Ley Orgánica de Hidrocarburos Gaseosos, como ley especial aplicable, exige a los particulares una licencia por parte del Estado para el ejercicio de las actividades de exploración y explotación de este tipo de hidrocarburos en el país. Ahora bien, la eventual discusión que se pueda derivar sobre la naturaleza jurídica de la licencia y su eventual asimilación a una concesión, por considerarse ambos actos propios del Derecho Administrativo, es un tema interesante; sin embargo, es un tema que escapa del objetivo del presente Artículo Académico.

En cambio es pertinente con respecto al objeto del presente trabajo, considerar el resto del contenido constitucional del Artículo 302 de la Carta Magna, el cual consagra el principio de promoción de Participación y Contenido Nacional, bajo los términos siguientes: "El Estado promoverá la manufactura nacional de materias primas provenientes de la explotación de los recursos naturales no renovables, con el fin de asimilar, crear e innovar tecnologías, generar empleos y crecimiento económico, y crear riqueza y bienestar para el pueblo" (subrayado del autor).

Como punto de partida es curioso resaltar la idea de industrializar los hidrocarburos en el país como fuente de empleos e ingresos para el Estado, en cumplimiento del mandato constitucional, no es nueva. De hecho, desde 1949, mediante el Decreto 131 de la Junta de Gobierno hasta la fecha, se ha buscado promover el uso de los hidrocarburos como fuente para la fabricación de bienes y prestaciones de servicios nacionales, tanto para la industria petrolera nacional como para el resto de los sectores económicos del país. Hasta la presente fecha han pasado más de 65 años desde la primera iniciativa sobre la manufactura nacional de materia prima, y con ello, varios gobiernos han intentado promover efectivamente la participación del sector privado venezolano en las actividades de los hidrocarburos en el país.

No obstante, en la actualidad se han adoptado varias normas constitucionales destinadas a promover e impulsar la política de manufactura de materia prima proveniente de los recursos naturales en el país. A manera de ejemplo, se pueden encontrar los principios de:

$\neg \quad$ Participación de los sectores público y privado en armonía, en cooperación, no necesariamente en sociedad u otra forma de participación en el desarrollo sostenible de la economía nacional (Const., 1999, art. 299);

$\neg \quad$ Reserva al Estado del uso de la política comercial para defender las actividades económicas de las empresas nacionales públicas y privadas (Const., 1999, art. 301);

$\neg \quad$ Promoción de la manufactura nacional de materias primas provenientes de la explotación de los recursos naturales no renovables con el objeto de crear e innovar tecnologías, generar empleo, crecimiento económico, crear riqueza y bienestar para el pueblo (Const., 1999, art. 302);

$\neg \quad$ Protección y promoción de la pequeña y mediana industria, cooperativas, cajas de ahorro, así como también la empresa familiar (Const., 1999, art. 308); y

$\neg \quad$ Financiamiento de la inversión real productiva, la educación y la salud, como producto del ingreso generado por la explotación del subsuelo y los minerales (Const., 1999, art. 311). 
Con relación al alcance del contenido completo del Artículo 302 de la Constitución, es oportuno resaltar que, dentro del referéndum constitucional celebrado en Venezuela en el año 2007, el Ejecutivo nacional presentó una propuesta para modificar varios (i.e., 69) artículos de la Constitución aprobada en 1999, propuesta que fue rechazada en su oportunidad, incluyendo el Artículo 302. Dicha proposición incorporaba los siguientes elementos:

$\neg \quad$ Elevación a -rango constitucional- de la reserva legal que había sido delegada a la Ley orgánica respectiva (i.e., Ley Orgánica de los Hidrocarburos), mediante la reserva directa de las actividades identificadas en dicha Ley Orgánica, es decir, de las actividades de exploración y explotación de los hidrocarburos, así como de las de recolección, transporte, almacenamiento inicial y las de las obras requeridas para el ejercicio de las actividades mencionadas;

$\neg \quad$ Extensión de las actividades bajo reserva, es decir, pasando de la reserva legal de la industria petrolera, como término especifico, a la reserva legal de la industria de los hidrocarburos como término general, la cual incluía a los hidrocarburos gaseosos, semi-sólidos y sólidos, además de los mencionados hidrocarburos líquidos;

$\neg \quad$ Determinación del destino de la materia prima manufacturada, así como de las innovaciones de tecnologías nacionales a áreas como la Faja Petrolífera del Orinoco (localizada al sur de Venezuela), los cinturones gasíferos tierra adentro y mar afuera, y los corredores petroquímicos;

$\neg \quad$ Elevación -a rango constitucional- de la facultad del Estado-Empresario/Socio (i.e., Ejecutivo nacional) para ejercer directamente las actividades bajo reserva, precisando también que las mismas podían ser ejercidas por entes o empresas de su exclusiva propiedad, o por medio de empresas mixtas en las cuales el Estado como socio tenga el control de las operaciones y la mayoría accionaria; y

$\neg \quad$ Exigencia de adecuar los negocios existentes (i.e., licencias de gas otorgadas antes de 2007) en materia de hidrocarburos gaseosos a un nuevo ordenamiento jurídico por adoptarse mediante ley ${ }^{11}$.

\section{3.- Propiedad de las acciones de la empresa estatal Petróleos de Venezuela, S.A. (PDVSA) - Casa Matriz (Estado-Empresario/Socio)}

El Artículo 303 de la Constitución de la República de Venezuela, ubicado dentro del Sistema Socioeconómico del Estado y, en particular, en el Capítulo correspondiente al Régimen Socioeconómico y la Función del Estado en la Economía, reserva al Estado venezolano la totalidad de las acciones de la empresa estatal Petróleos de Venezuela, S.A. (PDVSA). En este sentido, el Estado no solamente conserva por razones de soberanía económica, política y

\footnotetext{
${ }^{11}$ El texto completo de la reforma propuesta al Artículo 302 de la Constitución, era el siguiente:

El Estado se reserva, por razones de soberanía, desarrollo e interés nacional, la actividad de explotación de los hidrocarburos líquidos, sólidos y gaseosos, así como su recolección, transporte y almacenamiento iniciales y las obras que estas actividades requieran. El Estado promoverá la manufactura nacional procesando las correspondientes materias primas, asimilando, creando e innovando tecnologías nacionales, especialmente en lo que se refiere a la Faja Petrolifera del Orinoco, los cinturones gasiferos tierra adentro y mar afuera y los corredores petroquímicos, con el fin de desarrollar las fuerzas productivas, impulsar el crecimiento económico y lograr la justicia social.

El Estado mediante ley orgánica podrá reservarse cualquier otra actividad relacionada con los hidrocarburos.

Las actividades reservadas se ejercerán por el Ejecutivo Nacional directamente, o por medio de entes o empresas de su exclusiva propiedad, o por medio de empresas mixtas en las cuales tenga el control y la mayoría accionaria.

La adecuación al nuevo ordenamiento de los negocios existentes en materia de hidrocarburos gaseosos se hará mediante ley.
} 
de estrategia nacional la empresa estatal PDVSA, sino también la totalidad de las acciones del ente creado para el manejo de la industria petrolera.

Al respecto, el Artículo 303 mencionado establece que "Por razones de soberanía económica, política y de estrategia nacional, el Estado conservará la totalidad de las acciones de Petróleos de Venezuela, S.A., o del ente creado para el manejo de la industria petrolera, exceptuando la de las filiales, asociaciones estratégicas, empresas y cualquier otra que se hay a constituido o se constituya como consecuencia del desarrollo de negocios de Petróleos de Venezuela, S.A." (subrayado del autor).

La anterior norma constitucional es la materialización de la figura del Estado como Estado-Empresario/Socio, que participa en la actividad y los negocios relacionados con las actividades destinadas al uso y aprovechamiento de los hidrocarburos en el país.

El Artículo 303 de la Constitución se concentra en tres puntos de importancia:

$\neg \quad$ Conservación de la totalidad de las acciones de Petróleos de Venezuela, S.A., es decir, las acciones correspondientes a la Caza Matriz.

Este punto tiene mayor connotación cuando se trata de considerar y constituir garantías sobre las acciones de la mencionada empresa, ya que su eventual compromiso legal se vería afectado en caso de que deban ejecutarse dichas garantías por cualquier decisión judicial o arbitral en virtud de la inejecutabilidad de la sentencia, por violación de una norma de rango constitucional.

$\neg \quad$ Preservación de la totalidad de las acciones del ente creado para el manejo de la industria petrolera.

En este punto surge nuevamente la discusión sobre el alcance del término industria petrolera, y su inclusión o no de la industria del gas.

En cualquier caso, la empresa creada para el manejo de la industria del gas en Venezuela es, en la actualidad, PDVSA Gas, S.A., la cual es una filial de las más de 200 filiales que posee la antes mencionada empresa estatal/casa matriz Petróleos de Venezuela, S.A. a nivel nacional e internacional.

Por ser PDVSA Gas, S.A. una filial de la Casa Matriz, como cualquiera otra de las 200 filiales, entonces PDVSA Gas podría ser considerada dentro del supuesto de la norma constitucional sobre la excepción a la conservación de acciones por parte del Estado. Sin embargo, distinto sería el caso si el accionista de PDVSA Gas, S.A. es el Estado venezolano directamente, en cuyo caso tendría lugar, una vez más, la discusión sobre el alcance de la disposición legal en referencia y la incorporación de la industria del gas dentro de la noción sobre industria petrolera.

$\neg \quad$ Exclusión de la conservación de la totalidad de acciones por parte del Estado: 
- $\quad$ Filiales de la Casa Matriz, i.e., Petróleos de Venezuela, S.A., la cual posee en la actualidad más de 200 filiales y subsidiarias a nivel nacional e internacional;

- $\quad$ Extintas asociaciones estratégicas celebradas en el marco de la Apertura Petrolera de los años 90;

- Empresas y cualquier otra sociedad que se hayan constituido antes de la entrada en vigencia de la Constitución de 1999; y

- Empresas y cualquier otra sociedad que se constituyan, luego de la entrada en vigencia de la mencionada Constitución de 1999, como consecuencia del desarrollo de negocios de Petróleos de Venezuela, S.A.

Por su parte, al igual que la propuesta de reforma del contenido completo del Artículo 302 de la Carta Magna, el Artículo 303 en referencia también fue sometido a consulta popular para una modificación en su redacción dentro del referéndum constitucional celebrado en Venezuela en el año 2007.

En esa oportunidad, se propuso una modificación bajo las siguientes premisas:

$\neg \quad$ Prohibía la privatización parcial o total de Petróleos de Venezuela, S.A., o del ente o empresa de propiedad exclusiva del Estado;

$\neg \quad$ Suprimía la necesidad de conservar la totalidad de las acciones de Petróleos de Venezuela, S.A., o del ente creado para el manejo de la industria petrolera;

$\neg \quad$ Eliminaba de la norma constitucional que impedía al Estado conservar la totalidad de las acciones de las filiales, asociaciones estratégicas, empresas y cualquier otra que se haya constituido o se constituya como consecuencia del desarrollo de negocios de Petróleos de Venezuela, S.A.;

$\neg \quad$ Ampliaba el alcance de la actividad reservada a las empresas del Estado, llevándolas de entes creados para el manejo de los hidrocarburos líquidos, a entes o empresas de propiedad exclusiva del Estado que desarrollen en el territorio nacional actividades reservadas y relacionadas con los hidrocarburos en general; y

$\neg \quad$ Elevaba a rango constitucional la competencia del ministerio del ramo para fiscalizar y ejercer el control sobre las actividades reservadas, incluyendo todas las que conforman la Cadena de Valor de los Hidrocarburos, desde la exploración hasta el expendio de productos ${ }^{12}$.

${ }^{12}$ El texto completo de la reforma propuesta al Artículo 303 de la Constitución, era el siguiente:

Por razones de soberanía económica, desarrollo e interés nacional, Petróleos de Venezuela S.A. y los entes o empresas de propiedad exclusiva del Estado que desarrollen en el territorio nacional actividades reservadas, no podrán ser privatizados total ni parcialmente.

El Ejecutivo Nacional, por órgano del ministerio con competencia en la materia, fiscalizará y ejercerá el control sobre las actividades reservadas, así como sobre el transporte de los hidrocarburos y sus derivados en todo el territorio nacional, desde su extracción hasta el consumidor final en el mercado doméstico, o hasta los puertos y puntos de exportación. 


\section{3.- Importancia de los principales sistemas jurídicos y su impacto en el negocio de los hidrocarburos}

Un aspecto de importancia que deriva la coexistencia de la industria petrolera venezolana y los distintos roles y funciones del Estado-Anfitrión es la identificación y el conocimiento del Derecho Aplicable a la relación jurídica que pueda existir entre los distintos actores de la Cadena de Valor de los Hidrocarburos y órganos o entes del mencionado Estado-Anfitrión. En general debe entenderse como Derecho Aplicable al conjunto de principios, leyes e instituciones que forman parte de un determinado sistema jurídico.

Con relación a los sistemas jurídicos es necesario conocer que existen varios tipos de sistemas jurídicos en el mundo, los cuales han jugado un papel clave en el desarrollo histórico de los principios legales y reglas que se aplican a las relaciones jurídicas producto del uso y aprovechamiento de los hidrocarburos.

En la actualidad, estos sistemas jurídicos son principalmente dos: i) el sistema de Derecho Civil, el cual deriva del Derecho Romano-Germánico, y se traduce en la codificación de conductas y costumbres humanas mediante normas, leyes u otros instrumentos normativos; y ii) el sistema de Derecho Común, que tiene sus orígenes en la temprana centralización de las cortes en la época de Henry II en Inglaterra y que se ha materializado en la figura conocida como precedente judicial ${ }^{13}$.

Muchos de los sistemas jurídicos antes mencionados fueron exportados por algunos países a sus respectivas colonias. De ahí que muchos de los sistemas en el continente americano son principalmente influencia de Derecho Civil o de Derecho Común.

Esta exportación de sistemas también se ha materializado mediante modelos contractuales que, por ejemplo, en el sector de los hidrocarburos han sido principalmente importados del sistema anglosajón (i.e., Derecho Común) a otros países petroleros no anglosajones y carentes de experiencia en ese sector. Por eso, se observa con frecuencia en el sector de los hidrocarburos, contratos detallados (i.e., tipo manuales de uso) que tienden a definir todos y cada uno de los supuestos de hecho que puedan tener lugar durante el desarrollo de la relación jurídico-comercial, los cuales se rigen principalmente por el principio de la autonomía de la voluntad de las partes.

En contraposición se encuentran los modelos contractuales utilizados en los sistemas de Derecho Civil, cuyos contratos son menos complejos y extensos, y sus principios rectores están principalmente codificados en la ley, donde existen normas de orden público que no pueden ser relajadas por las partes, aunque exista el mencionado principio de autonomía de la voluntad de las partes.

Pese a que en la actualidad pareciera existir un emergente balance entre los dos principales sistemas jurídicos del mundo, es decir el Derecho Civil y el Derecho Común, debido a la codificación que se está presentando en los sistemas anglosajones por un lado, y por el otro el recurrente uso del precedente judicial en el sistema de

\footnotetext{
${ }^{13}$ Hay otros sistemas jurídicos como lo son el Derecho Socialista, el Derecho Islámico y el Derecho Comunista. Se recomienda leer a Merryman, J. H. (2008) La tradición jurídica romano-canónica, Ciudad de México, Fondo de Cultura Económica; Eddey, K. (1982) The English Legal System, 3rd ed., London, Sweet \& Maxwell; Elliott, C., Jeanpierre, E., y Vernon, C., (2006) French Legal System, 2nd ed., Inglaterra, Pearson Longman; Patrick Glenn, H., (2010) Legal Traditions of the World, 4th ed., Reino Unido, Oxford University Press.
} 
Derecho Civil, es oportuno acotar que la estructura y el negocio de los hidrocarburos mantiene una gran influencia de principios e instituciones provenientes del sistema anglosajón conocido como Derecho Común.

Por lo anterior, es necesaria la importantísima tarea de adquirir conocimientos básicos de ambos sistemas, ya que se observa con frecuencia a profesionales formados en un sistema jurídico específico (i.e., sistema de Derecho Común) interpretando y aplicando normas y principios propios de otro sistema (i.e., sistema de Derecho Civil) o viceversa.

Esta última práctica es bastante común en algunos asesores legales de los actores de la Cadena de Valor de los Hidrocarburos. De hecho, la influencia de esta práctica se mantiene vigente en muchos de los modelos contractuales que se utilizan para el ejercicio de las actividades relativas a los hidrocarburos.

La mejor manera de entender y atender la anterior problemática es mediante el estudio de las normas de derecho público, como el Derecho Constitucional y el Derecho Administrativo, que no solo contienen los principios rectores que rigen en el Estado receptor de la inversión, sino también los principios rectores que sirven como marco legal que establece las bases mínimas para garantizar el Estado de Derecho de cualquier particular dentro de una sociedad democrática ${ }^{14}$. La materialización de lo antes expuesto se puede apreciar en muchos modelos contractuales como por ejemplo: concesiones, licencias, asociaciones, contratos de servicios (es decir, de bienes y servicios operativos), contratos marco de servicios (i.e., master services agreements), contratos de exploración a riesgo y ganancias compartidas, entre otros ${ }^{15}$.

Los principales esquemas contractuales utilizados para el ejercicio de las actividades relativas al uso y aprovechamiento de los hidrocarburos, no son considerados ni analizados en el presente Artículo Académico, cuyo objeto principal es despertar curiosidad académica sobre uno de los principales problemas que enfrentan los distintos actores que conforman la industria de los hidrocarburos: su coexistencia con los distintos roles y funciones del Estado-Anfitrión en el negocio petrolero y gasífero, y la relevancia de la interpretación y aplicación de normas jurídicas derivadas de la anterior coexistencia en controversias y/o discrepancias nacionales e internacionales, en particular, cuando son estudiadas y analizadas bajo los principios propios de los principales sistemas jurídicos del mundo.

\section{4.- Resumen}

La compleja estructura del negocio de los hidrocarburos en Venezuela requiere contar con algunos conocimientos básicos de los elementos constitucionales que regulan dicha estructura. Este conocimiento básico ayuda a comprender figuras como el dominio sobre los yacimientos y las reservas de hidrocarburos, la propiedad de los yacimientos, la reserva de la actividad, el ejercicio de las actividades y el marco jurídico que aplica a cada una de ellas.

Las normas constitucionales estudiadas en el presente Artículo Académico son el fundamento jurídico que dan forma institucional a lo que se conoce como la trinidad de roles del Estado en la economía productiva del país; es decir, el Estado-Propietario, el Estado-Administrador/Regulador y el Estado Empresario/Socio.

14 Véase, para mayor detalle sobre este punto: Mata García, C. R., (2016), International Investment and Regulatory Disputes - Applying Principles of Administrative Law to Investor-State Treaty Arbitrations, Germany, Scholar's Press.

15 Para mayor detalle sobre los modelos contractuales petroleros, se recomienda leer: Duval, C., Le Leuch, H., Pertuzio, A., y Lang Weaver, J., (2009) International Petroleum Exploration and Exploitation Agreements; Legal, Economic \& Policy Aspects, 2nd ed., New York, Barrows; Pinto Oliveros, S. (2016), Contratos petroleros en América Latina: una introducción, Derecho de la energía en América Latina, V. Hernández-Mendible (Dir.), Bogotá, Universidad Externado de Colombia, en imprenta. 
La anterior diferenciación es sumamente importante para el lector y el estudioso del Derecho de los Hidrocarburos, al momento de negociar con el Estado dueño de los recursos naturales.

En la teoría cada uno de esos roles tiene un fundamento jurídico distinto, pero en la práctica se pueden encontrar funcionarios públicos ejerciendo varias facultades o competencias que incluyen el ejercicio conjunto de dos roles del Estado como lo son el del Estado-Administrador/Regulador y el del Estado-Empresario/Socio, como, en Venezuela, es el caso del ministro con competencia en hidrocarburos y presidente de Petróleos de Venezuela, S.A. (PDVSA); el del ministro con competencia en energía eléctrica y presidente de Corporación Eléctrica Nacional, S.A. (CORPOELEC), entre otros.

Los anteriores ejemplos son la materialización del ejercicio conjunto por parte de un mismo funcionario de actividades consideradas como actos de dominio (iure imperii), en contraposición a los actos reputados como actos de administración o gestión (iure gestionis).

Es necesario alertar sobre la necesidad de tener claro, desde el punto de vista jurídico, el rol con el cual actúa un funcionario teniendo en cuenta la diversidad de roles del Estado, ya que con frecuencia se crean expectativas que una vez asumidas bajo el principio de la buena fe, son perfectamente válidas en un sistema jurídico determinado (e.g., la expectativa legítima bajo el Derecho Común), mientras que, bajo otro sistema jurídico como el de Derecho Civil, no serían válidas dichas expectativas sin un fundamento legal determinado para la toma de la decisión que se adopta, en especial si son decisiones que afectan principios de orden público.

La reflexión anteriormente formulada toma mayor relevancia para los profesionales del Derecho formados en el sistema del Derecho Común, donde existe la figura de la expectativa legítima en la que una simple declaración de un funcionario en ejercicio de sus funciones puede crear obligaciones para el Estado, cosa que no sucede - tan fácilmente- en el sistema de Derecho Civil, donde debe existir una delegación legal expresa para ejercer dicha función y por ende comprometer legalmente al Estado en cualquiera de sus roles (i.e., contar con capacidad jurídica para comprometer y asumir derechos y obligaciones en nombre y por cuenta del Estado). 


\section{*Bibliografía}

BENDAHAN, D. (1969) La legislación venezolana sobre hidrocarburos. Caracas, Empresas El Cojo.

BOSCÁN, I. (2002) La actividad petrolera y la nueva Ley Orgánica de Hidrocarburos. Caracas, Fundación Estudios de Derecho Administrativo.

CABELLO, J. R. (2002) Vigencia de los hidrocarburos. Venezuela, CIED.

Constitución de la República Bolivariana de Venezuela [Const.] (1999), Gaceta Oficial de la República Bolivariana de Venezuela No 36.860 de fecha 30 de diciembre de 1999.

DE LA PLAZA, S. (1997) Petróleo y soberanía nacional. Mérida, Consejo de Desarrollo Científico, Humanístico y Tecnológico-Universidad de Los Andes, tomos I \& II.

MATA GARCIA, C. R. (2016) International Investment and Regulatory Disputes - Applying Principles of Administrative Law to Investor State Treaty Arbitrations. Ale mania, Editorial Scholars' Press.

MATA GARCÍA, C. R. (2016) Manual de Derecho de los Hidrocarburos en Venezuela. Venezuela, Editorial Arte.

RONDÓN DE SANSÓ, H. (2008) El régimen jurídico de los hidrocarburos. El impacto del petróleo en Venezuela. Caracas, Hildegard Rondón de Sansó.

SCHRIJVER, N. (2008) Sovereignty over Natural Resources - Balancing Rights and Duties. Rein Undo. Cambridge Studies in International and Comparative Law. Cambridge University Press. 